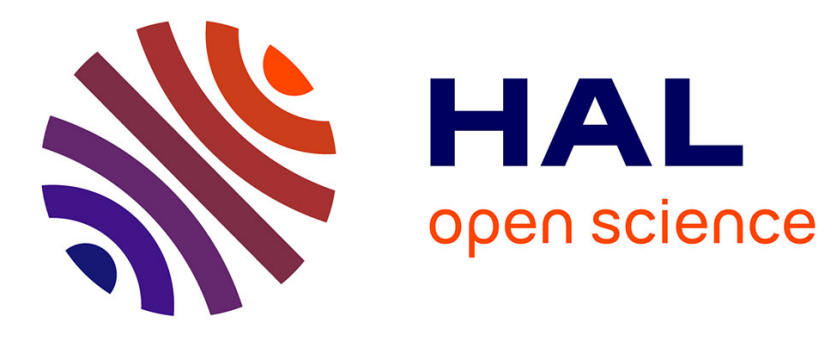

\title{
Finite element simulation of magnesium alloys laser beam welding
}

Asma Belhadj, Jamel Bessrour, Jean-Eric Masse, Mahmoud Bouhafs, Laurent Barrallier

\section{- To cite this version:}

Asma Belhadj, Jamel Bessrour, Jean-Eric Masse, Mahmoud Bouhafs, Laurent Barrallier. Finite element simulation of magnesium alloys laser beam welding. Journal of Materials Processing Technology, 2010, 210 (9), pp.1131-1137. 10.1016/j.jmatprotec.2010.02.023 . hal-01059759

\section{HAL Id: hal-01059759 https://hal.science/hal-01059759}

Submitted on 1 Sep 2014

HAL is a multi-disciplinary open access archive for the deposit and dissemination of scientific research documents, whether they are published or not. The documents may come from teaching and research institutions in France or abroad, or from public or private research centers.
L'archive ouverte pluridisciplinaire HAL, est destinée au dépôt et à la diffusion de documents scientifiques de niveau recherche, publiés ou non, émanant des établissements d'enseignement et de recherche français ou étrangers, des laboratoires publics ou privés. 


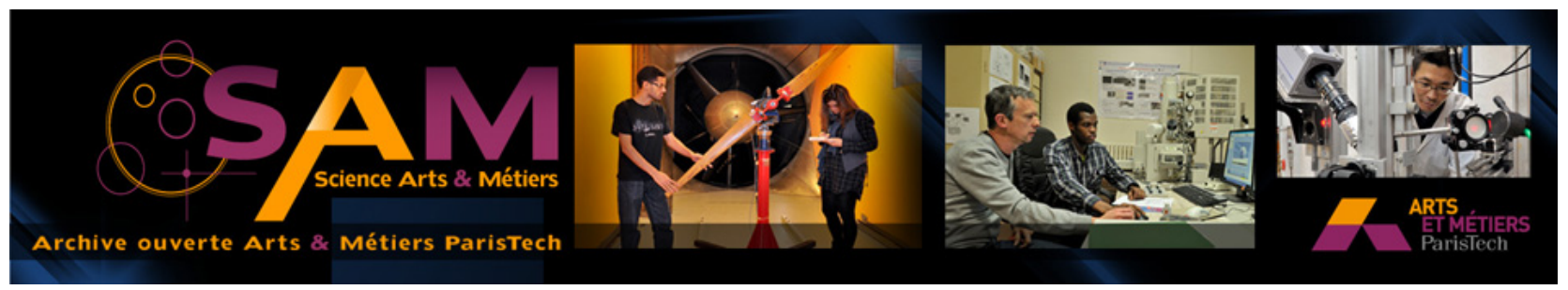

Science Arts \& Métiers (SAM)

is an open access repository that collects the work of Arts et Métiers ParisTech researchers and makes it freely available over the web where possible.

This is an author-deposited version published in: http://sam.ensam.eu

Handle ID: .http://hdl.handle.net/10985/8437

\section{To cite this version :}

Asma BELHADJ, Jamel BESSROUR, Jean-eric MASSE, Mahmoud BOUHAFS, Laurent BARRALLIER - Finite element simulation of magnesium alloys laser beam welding - Journal of Materials Processing Technology - Vol. 210, n9, p.1131-1137 - 2010 


\title{
Finite element simulation of magnesium alloys laser beam welding
}

\author{
Asma Belhadj ${ }^{\mathrm{a}, \mathrm{b}, *}$, Jamel Bessrour ${ }^{\mathrm{a}}$, Jean-Eric Masse ${ }^{\mathrm{b}}$, Mahmoud Bouhafs ${ }^{\mathrm{a}}$, Laurent Barrallier $^{\mathrm{b}}$ \\ a MA2I Research Unit, École Nationale d'Ingénieurs de Tunis, BP 37, Le Belvédère 1002, Tunis, Tunisia \\ b MécaSurf Laboratory, Arts et Métiers ParisTech, 2 cours des Arts et Métiers, 13617, Aix en Provence, France
}

\section{Keywords:}

FEM simulation

Laser welding

Magnesium alloy

Thermal analysis

\begin{abstract}
A B S T R A C T
In this paper, a three-dimensional finite element model is developed to simulate thermal history magnesium-based alloys during laser beam welding. Space-time temperature distributions in weldments are predicted from the beginning of welding to the final cooling. The finite element calculations were performed using Cast3M code with which the heat equation is solved considering a non-linear transient behaviour. The applied loading is a moving heat source that depends on process parameters such as power density, laser beam dimensions and welding speed, and it is associated to moving boundary conditions. Experiments were carried out to determine temperature evolution during welding and to measure the laser weld width. By comparing the thermal model answers with the measurements, it is found that numerical simulations results are in a good agreement with the experimental data.
\end{abstract}

\section{Introduction}

The requirement to reduce fuel consumption and gas emission entices auto industries to replace dense materials, not only steels and cast iron alloys but even aluminium alloys, by magnesiumbased alloys. Friedrich and Mordike (2006) reported that these materials have the lowest density of conventional casting metals (33\% lighter than aluminium alloys), and other attractive characteristics' such as excellent specific strength, good castability and recyclability.

With the increasing uses of magnesium alloys especially in automotive industry, it was important to develop assembly processes. Today, magnesium alloy components may be joined using mechanical fasteners and some welding techniques with high energy density and shielding gases to protect the metal from the oxygen action. Basically, TIG and MIG processes are the most used methods for magnesium alloys welding. However, some disadvantages of these techniques, like low welding speeds, large heat affected zone (HAZ) and high residual stress and distortion of joints, limit their uses. For these reasons, magnesium alloys weldability by innovative welding techniques, like laser beam welding (LBW), has been studied during the last decade. Dhahri et al. (2000, 2001) studied

\footnotetext{
* Corresponding author at: ENSAM, MécaSurf Laboratory, Arts et Métiers ParisTech, 2 cours des Arts et Métiers, 13617, Aix En Provence, France. Tel.: +33 669636514; fax: +33 442938115 .

E-mail addresses: assma_belhadj@yahoo.fr (A. Belhadj), jamel.bessrour@enit.rnu.tn (J. Bessrour), Jean-Eric.Masse@ensam.fr (J.-E. Masse), mahmoud.bouhafs@enit.rnu.tn (M. Bouhafs), laurent.barrallier@ensam.eu (L. Barrallier).
}

laser beam weldability of AZ91 and WE43 magnesium-based alloys. Using a $\mathrm{CO}_{2}$ laser source, they have determined welding parameters to joint 6 and $2 \mathrm{~mm}$ thickness sheets. Some studies recently published by Quan et al. (2008) were interested on laser welding of dissimilar magnesium alloys. Joining of magnesium-based alloys using focused laser beam is an interesting research field that is still in progress.

On the back of this, laser welding process is advantageous, it leads to small heat affected zone, deep and narrow fusion zone, high processing speed and low residual stresses and weldment distortion. But experimental investigations are long and expensive so it is important to develop numerical techniques to simulate thermal and mechanical consequences of this welding process. Numerical results can be used to explain the physics of some complex phenomena in welding process and to optimize welding parameters. Several numerical models have been developed to determine temperature profiles and stresses distribution during laser beam welding. Nevertheless, most of investigations refer to steel structural components and recently to aluminium alloys. Spina et al. (2007) established a thermo-mechanical model to predict temperature and analyse the welding parameters influence on sample displacement after cooling during AA5083 aluminium alloy laser welding. Using coupled analyses, Moraitis and Labeas (2008) modelled the laser welding of 6061 aluminium-based alloys. Considering a cone shaped keyhole as thermal source, they predicted residual stresses distribution on $2 \mathrm{~mm}$ thickness sheets.

To the author's knowledge, no transient numerical analysis has been made for laser welding magnesium alloys; published investigations are limited to local problems like those proposed by Abderrazak et al. (2008, 2009a,b). In their work, they studied local 


\begin{tabular}{|c|c|}
\hline \multicolumn{2}{|c|}{ Nomenclature } \\
\hline C & specific heat $\left(\mathrm{J} \mathrm{kg}^{-1}{ }^{\circ} \mathrm{C}^{-1}\right)$ \\
\hline$d$ & laser beam diameter $(\mu \mathrm{m})$ \\
\hline$e$ & piece thickness (mm) \\
\hline$h$ & convective coefficient $\left(\mathrm{W} \mathrm{m}^{-2}{ }^{\circ} \mathrm{C}^{-1}\right)$ \\
\hline$i$ & increment \\
\hline $\mathrm{np}_{\mathrm{s}}$ & time step number during welding stage \\
\hline$t$ & time $(\mathrm{s})$ \\
\hline$t_{r 0}$ & initial time of cooling stage (s) \\
\hline$T$ & temperature $\left({ }^{\circ} \mathrm{C}\right)$ \\
\hline$T_{\mathrm{i}}$ & initial temperature $\left({ }^{\circ} \mathrm{C}\right)$ \\
\hline$T_{\mathrm{S}}$ & surface temperature $\left({ }^{\circ} \mathrm{C}\right)$ \\
\hline$T$ & fluid temperature $\left({ }^{\circ} \mathrm{C}\right)$ \\
\hline$T_{0}$ & ambient temperature $\left({ }^{\circ} \mathrm{C}\right)$ \\
\hline$P_{\mathrm{ak}}$ & keyhole absorbed power (W) \\
\hline$P_{\text {ap }}$ & plasma absorbed power (W) \\
\hline$q$ & surface heat density $\left(\mathrm{W} \mathrm{m}^{-2}\right)$ \\
\hline$Q$ & volume heat density $\left(\mathrm{W} \mathrm{m}^{-3}\right)$ \\
\hline$V$ & welding speed $\left(\mathrm{m} \mathrm{min}^{-1}\right)$ \\
\hline$x_{\mathrm{i}}$ & coordinates $(\mathrm{mm})$ \\
\hline$(x, y, z)$ & Cartesian coordinates (mm) \\
\hline \multicolumn{2}{|c|}{ Greek symbol } \\
\hline$\varepsilon$ & emissivity \\
\hline$\Delta t_{\mathrm{s}}$ & time step-welding stage $(\mathrm{s})$ \\
\hline$\Gamma_{\text {ext }}$ & external surface $\left(\mathrm{mm}^{2}\right)$ \\
\hline$\Gamma_{\mathrm{c}}$ & contact surface $\left(\mathrm{mm}^{2}\right)$ \\
\hline$\Gamma_{\text {p.i }}$ & plasma lighted surface at i position $\left(\mathrm{mm}^{2}\right)$ \\
\hline$\Gamma_{\mathrm{e} . \mathrm{i}}$ & keyhole lighted surface at i position $\left(\mathrm{mm}^{2}\right)$ \\
\hline$\lambda$ & thermal conductivity $\left(\mathrm{W} \mathrm{m}^{-1}{ }^{\circ} \mathrm{C}^{-1}\right)$ \\
\hline$\Omega$ & volume $\left(\mathrm{mm}^{3}\right)$ \\
\hline$\rho$ & density $\left(\mathrm{kg} \mathrm{m}^{-3}\right)$ \\
\hline$\tau$ & laser-matter interaction time $(\mathrm{s}$ \\
\hline
\end{tabular}

parameter effects on molten pool formation during $\mathrm{CO}_{2}$ laser welding of AZ91 and WE43 magnesium alloys.

In the present study, the thermal history of butt-joint laser beam welding of thin AM60 magnesium alloys plates was simulated. A transient non-linear three-dimensional model was developed, within a finite elements computational code Cast3M, in order to predict the space-time distribution of temperature in magnesium alloy sheets from the beginning of welding until the return to the thermal equilibrium at cooling. The developed model took into account the non-linearity introduced by the loading which depends on time and space, and by thermo-physical properties which are temperature dependent. The heat source was introduced as mobile volume source modelling the power density produced by the laser spot during laser-matter interaction. As well as, in this model, a surface thermal source is introduced in order to take into account the effect of the plasma during laser welding.

Numerical results were presented in the form of isotherms at different times of treatment and instantaneous evolutions of the temperature in each point of the mesh. Simulated temperature evolutions were compared to those measured experimentally by thermocouples implanted in several points of the weldments. Predicted molten zone form during heating stage was also compared to weld morphology obtained by metallurgical investigations.

\section{Numerical simulation model}

During laser continuous wave welding process, the power density, produced by the focused beam, is very intense allowing the vaporization of metal directly under the beam. A thin hole, com-

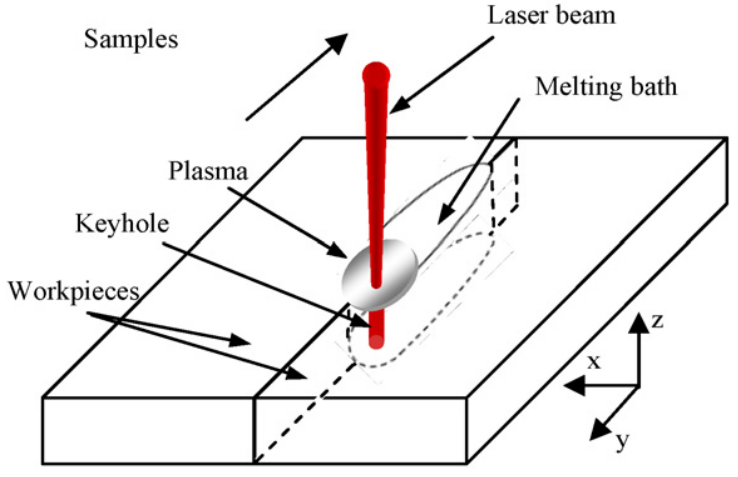

Fig. 1. Keyhole and plasma formation during laser welding.

posed of metallic vapors is created through the welded components (Fig. 1). This one, known as keyhole, transmits the laser beam energy to metal. During weldments moving, the keyhole is maintained under the laser beam and surrounded by molten metal which is solidified after beam moving allowing the assembly of the workpieces. The keyhole is protected by a shielding gas producing the plasma that constitutes a secondary heat source. The described physical phenomena were simulated through a numerical finite element model in order to simulate thermal behaviour of laser welded samples.

\subsection{Assumptions of simulation}

Some simplifying assumptions were adopted for the development of the numerical model. They concern on: (i) the reduction of field study by making use of symmetry. The thermal history of only one half of the assembly was predicted. (ii) Simulation was made considering that the laser beam moves at constant speed. We have also assumed (iii) a perfect contact between the two welded parts, (iv) an uniform power distribution in the keyhole and (v) an isotropic thermal behaviour during welding.

\subsection{Heat balance}

The developed thermal model results from the energy balance during laser beam welding. Two treatment phases were modelled.

(1) Stage I (Fig. 2): The applied loading was the combination of laser beam power density and surface heat flow due to the plasma. Boundary conditions are convection loss flows on external surface and radiation losses in lighted laser beam surface.

(2) Stage II: After applying the laser spot, the weldments cooled on free air. During cooling, laser beam was cancelled. We considered the temperature distribution at the end of heating phase as

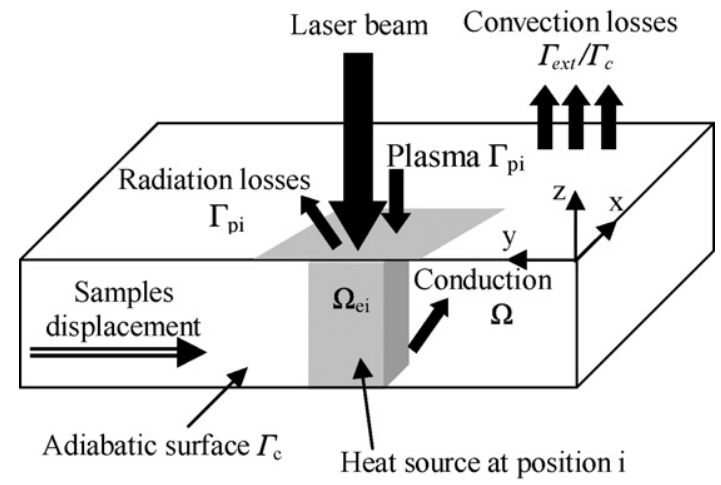

Fig. 2. Energy balance during laser welding process (stage I). 


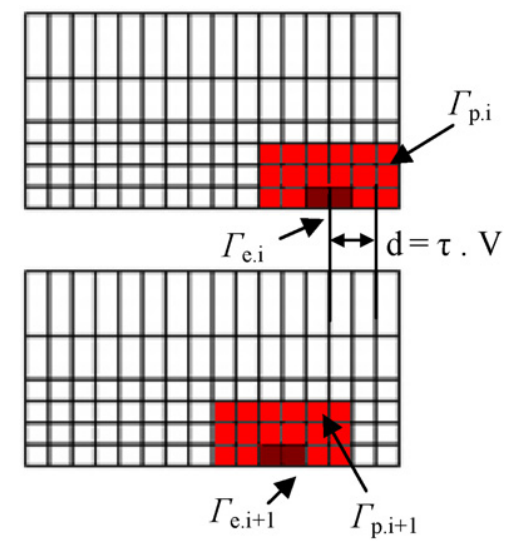

Fig. 3. Meshing of laser lighted surface.

initial condition and only convection losses on external surface as boundary conditions.

\subsection{Geometrical model}

The geometrical model of weldment was a three-dimensional mesh modelled using cubic elements with eight nodes and quadratic elements with four nodes. To introduce a mobile heat source, mesh construction must depend on laser beam dimension and welding rate. A dense mesh was used in the area along the weld line as shown in Fig. 3. Geometry dimensions were $60 \mathrm{~mm}$ in length $40 \mathrm{~mm}$ in width and $3 \mathrm{~mm}$ in thickness. The built mesh is composed of 17100 elements for 24080 nodes (Fig. 4).

\subsection{Thermal problem formulation}

Heat equation resolution, in non-linear transient state with a mobile volumetric heat source, allowed the determination of the space-time temperature evolution during welding.

- During stage I, the mathematical formulation is given by:

on $\Omega: \frac{\partial \rho(T) C(T) T\left(x_{\mathrm{i}}, t\right)}{\partial t}-\operatorname{div}\left(\lambda(T) \operatorname{grad} T\left(x_{\mathrm{i}}, t\right)\right)-Q=0$

The convection and radiation limit conditions are:

on $\Gamma_{\mathrm{p} . \mathrm{i}}: \lambda(T)\left(\operatorname{grad} T\left(x_{\mathrm{i}}, t\right)\right)_{\text {surface }}+\varepsilon \sigma\left(T\left(x_{\mathrm{i}}, t\right)^{4}-T_{\infty}^{4}\right)=q$

on $\Gamma_{\text {ext }} \backslash \Gamma_{\mathrm{c}}: \lambda(T)\left(\operatorname{grad} T\left(x_{i}, t\right)\right)_{\text {surface }}+h\left(T\left(x_{i}, t\right)-T_{\infty}\right)=0$

The adiabatic condition on the contact surface is:

on $\Gamma_{\mathrm{c}}: \lambda \operatorname{grad} T\left(x_{i}, t\right)=0$

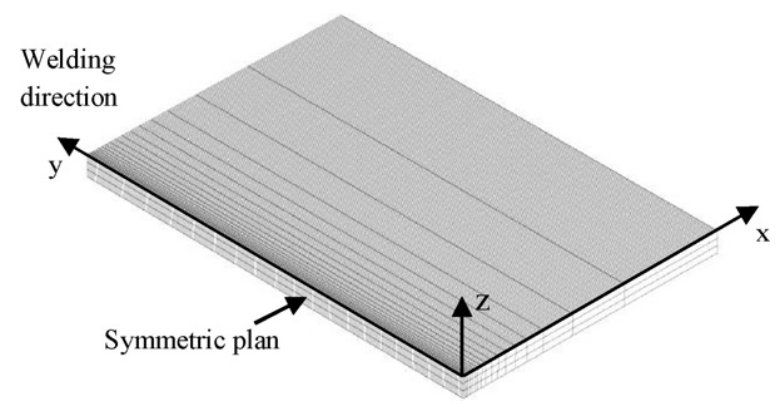

Fig. 4. Geometric model-meshing.
Table 1

Magnesium alloy properties evolution with temperature.

\begin{tabular}{lrrrrrr}
\hline$T\left({ }^{\circ} \mathrm{C}\right)$ & 0 & 40 & 120 & 200 & 500 & 700 \\
$\lambda\left(\mathrm{W} \mathrm{m}^{-1}{ }^{\circ} \mathrm{C}^{-1}\right)$ & 60 & 66 & 77 & 85 & 100 & 60 \\
$T\left({ }^{\circ} \mathrm{C}\right)$ & & & & & & \\
$\rho\left(\mathrm{kg} \mathrm{m}^{-3}\right)$ & 1792 & 1781 & 1774 & 1766 & 1730 & \\
& & & & & & \\
$T\left({ }^{\circ} \mathrm{C}\right)$ & 20 & 200 & 250 & 270 & 350 & 600 \\
$C\left(\mathrm{~J} \mathrm{~kg}^{-1}{ }^{\circ} \mathrm{C}^{-1}\right)$ & 1010 & 1080 & 1150 & 1145 & 1155 & 1300 \\
\hline
\end{tabular}

The initial condition is:

at $t=0: T\left(x_{i}, 0\right)=T_{0}$

- During stage II, mathematical formulation is given by:

on $\Omega: \frac{\partial \rho(T) C(T) T\left(x_{i}, t\right)}{\partial t}-\operatorname{div}\left(\lambda(T) \operatorname{grad} T\left(x_{i}, t\right)\right)=0$

The convection limits conditions are:

on $\Gamma_{\text {ext }} \backslash \Gamma_{\mathrm{c}}: \lambda(T)\left(\operatorname{grad} T\left(x_{i}, t\right)\right)_{\text {surface }}+h\left(T\left(x_{i}, t\right)-T_{\infty}\right)=0$

The adiabatic condition on the contact surface is:

on $\Gamma_{\mathrm{c}}: \lambda \operatorname{grad} T\left(x_{i}, t\right)=0$

The initial condition is the temperature distribution in the sample at the end of laser phase application:

at $t=t_{r 0}: T\left(x_{i}, t\right)=T_{\mathrm{np}_{\mathrm{s}}}$

\subsection{Heat sources model}

In the numerical model, the thermal loading was introduced as mobile volume heat source. Based on metallurgical observations of laser beam magnesium alloys weld made by Belhadj (2009) and Dhahri et al. $(2000,2001)$, the formed keyhole was considered cylindrical. It was modelled by a volume density power $Q$ that depends on laser beam diameter $d$ and keyhole absorbed power $P_{\mathrm{ak}}$ (Eq. (10)). In addition to the volume source, a surface density source $q$ introduced as boundary condition (Eq. (2)) modelling the plasma consequence. This depends on the plasma absorbed power $P_{\text {ap }}$ and plasma affected surface $S_{\text {plasma }}$ (Eq. (11)). Heat source model parameters were experimental data.

$Q=\frac{P_{\mathrm{ak}}}{V_{\mathrm{keyhole}}}=\frac{P_{\mathrm{ak}}}{e\left(\pi d^{2} / 4\right)}$

$q=\frac{P_{\mathrm{ap}}}{S_{\text {plasma }}}$

\subsection{Material data}

During laser welding process an important temperature gradient was produced between various parts of weldments, from the beginning to the end of treatment. Thermo-physic characteristics of material must be temperature depended. In their investigation on magnesium alloys MIG-welding simulation, Michailov et al. (2003) had used the evolution of thermal conductivity, density and specific heat according temperature. The values of these properties, shown in Table 1, are exploited in this work.

\subsection{Thermal problem resolution}

Thermal problem was solved using "PASAPAS" procedure. This Cast3M operator was used by Bessrour et al. (2002) to developed transient, non-linear and incremental calculations taking into consideration conduction, convection and radiation. The numerical scheme used for heat equation resolution was an implicit 


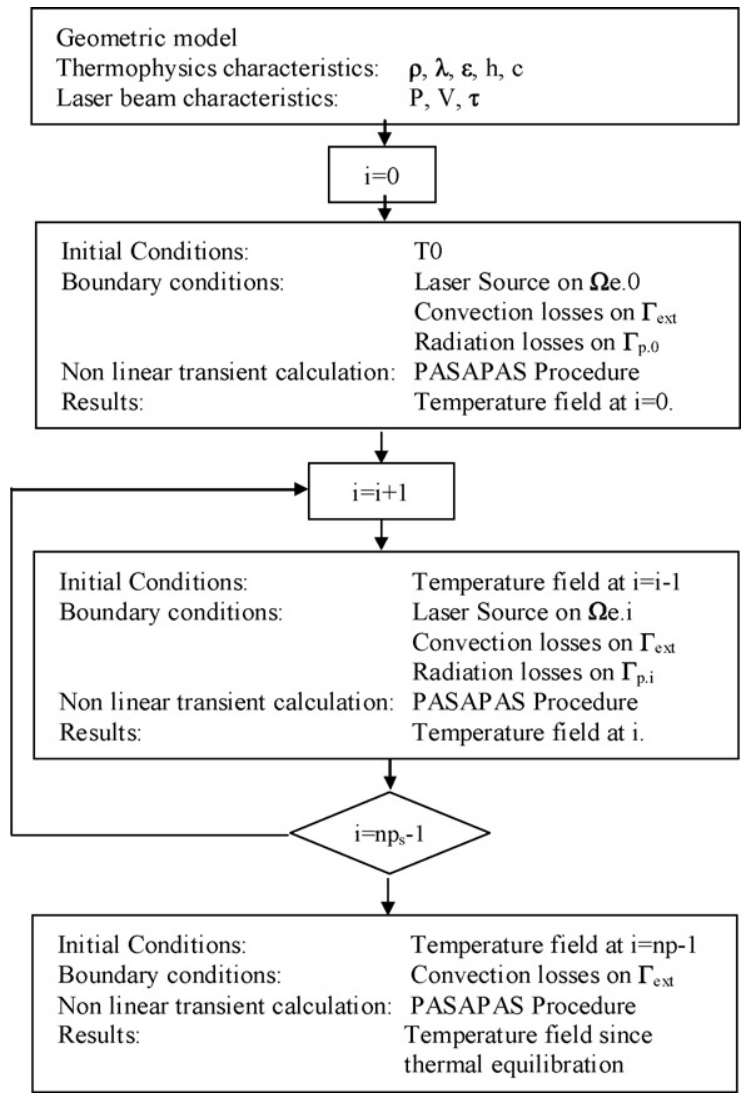

Fig. 5. Flowchart of numerical calculation.

schema with two time steps according to DUPONT2 algorithm and $\theta$-method for the first step.

The flow chart of Fig. 5 shows the procedure for FE calculation. The proposed numerical model simulated the whole thermal history of welded pieces laser welding and cooling. The number of laser spot positions $(\mathrm{np}=150)$ depends on sample length and keyhole diameter. The time step calculation $\Delta t_{s}$, in laser application stage, is in relation to the laser-matter interaction time given by Eq. (12):

$\tau=\mathrm{np}_{\mathrm{s}} \Delta t_{\mathrm{s}}=\frac{d}{V}=0.0057 \mathrm{~s}$

\section{Experimental investigations}

A number of welding tests were performed to optimize laser welding parameter for as-cast AM60 magnesium-based alloy. Welds were carried out using a Rofin $3 \mathrm{~kW} \mathrm{CW} \mathrm{CO}$ laser source generating a high quality beam ( $\mathrm{TEM}_{01}$ mode). The laser beam was focused with $50 \mathrm{~mm}$ focal length parabolic mirror and its diameter at the focal point was $d=400 \mu \mathrm{m}$.

Samples, machined in the form of $60 \mathrm{~mm} L \times 46 \mathrm{~mm} W \times 3 \mathrm{~mm}$ $T$ sheets, were positioned in the fixture system (Fig. 6) and welded using helium as shielding gas (Fig. 7). Tables 2 and 3 give respectively the chemical composition of welded material and optimized welding parameters used in experimental investigations.

To record temperature evolution during laser welding process, $1 \mathrm{~mm}$ diameter K-type thermocouples were used. As shown in Fig. 8, thermocouples were fixed near the weld at two different distances to the centre-line $\left(T_{1}, T_{2}\right)$ and at different axial locations (location in the advancing direction of welding $T_{2}, T_{3}$ ).

After welding, the microstructure of the different zones of the assembly was analysed using a high magnification zoom micro-

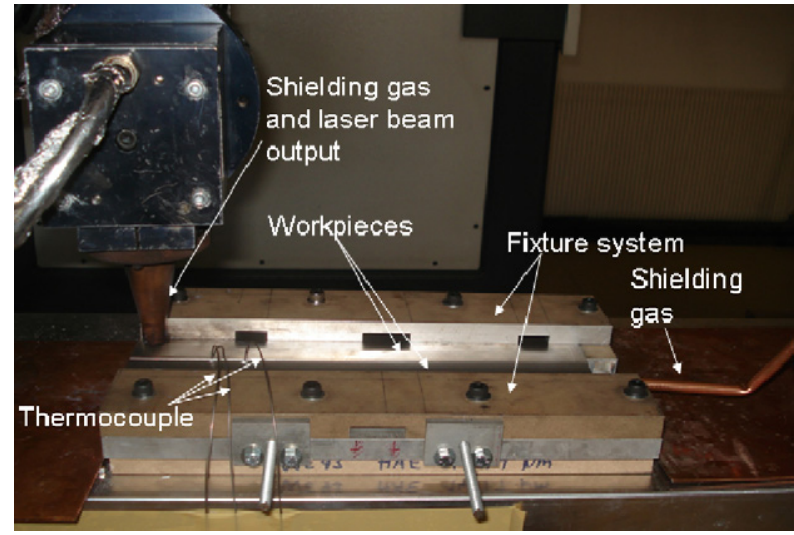

Fig. 6. Welding fixture with clamped AM60 magnesium alloy samples.

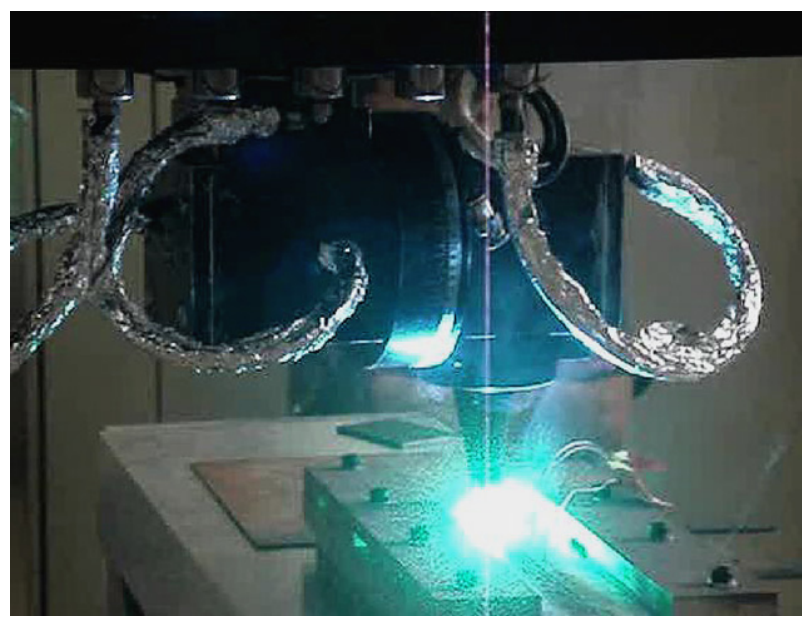

Fig. 7. Plasma creation during magnesium alloys laser welding.

Table 2

AM60 composition

\begin{tabular}{llllll}
\hline$\% \mathrm{Al}$ & $\% \mathrm{Mn}$ & $\% \mathrm{Zn}$ & $\% \mathrm{Si}$ & $\% \mathrm{Cu}$ & $\% \mathrm{Ni}$ \\
\hline $5.5-6.5$ & $0.1-0.4$ & $\leq 0.2$ & $\leq 0.2$ & $\leq 0.2$ & $\leq 0.03$ \\
\hline
\end{tabular}

Table 3

Welding parameters.

\begin{tabular}{llll}
\hline Laser power $(\mathrm{W})$ & $\begin{array}{l}\text { Velocity } \\
(\mathrm{mm} / \mathrm{min})\end{array}$ & $\begin{array}{l}\text { Focus point } \\
\text { (mm from } \\
\text { surface) }\end{array}$ & Shielding gas \\
\hline 3000 & $4.2 \mathrm{~m} / \mathrm{min}$ & 0 & $40 \mathrm{l} / \mathrm{min}, 2$ bars \\
\hline
\end{tabular}

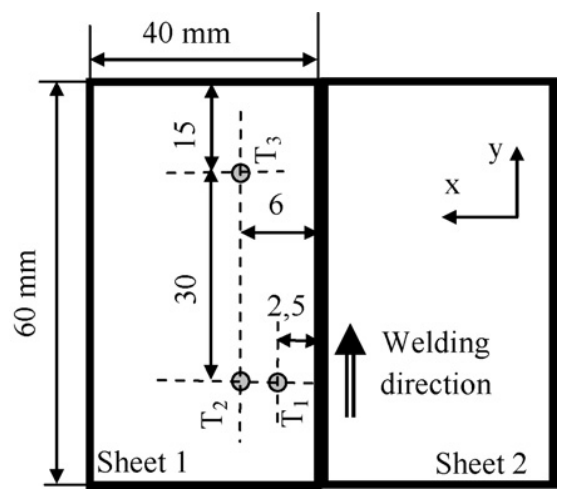

Fig. 8. Thermocouples position during welding. 
scope. Metallurgical samples were mounted by resin ground and polished using 180-1200-grit silicon carbide papers (SiC). Immediately after the last polishing step, the samples were washed with water, rinsed with methanol $\mathrm{CH}_{3} \mathrm{OH}$, and dried. A fine polishing was conducted using $0.5 \mu \mathrm{m}$ oil based diamond compounds. Samples were subsequently etched with acetic glycol etchant $(60 \mathrm{ml}$ ethylene glycol $\mathrm{C}_{2} \mathrm{H}_{6} \mathrm{O}_{2}, 20 \mathrm{ml}$ acetic acid $\mathrm{C}_{2} \mathrm{H}_{4} \mathrm{O}_{2}, 19 \mathrm{ml}$ water $\mathrm{H}_{2} \mathrm{O}$, $1 \mathrm{ml} \mathrm{HNO}_{3}$ ).

\section{Results and discussion}

As concern numerical study, results of FEM thermal model are given for $3 \mathrm{~mm}$ AM60 magnesium alloy sheet thickness. Processing parameters are those used for experimental investigations and specified in Table 3. For results figures, $(x, y, z)$ point coordinates are given in $\mathrm{mm}$.

Fig. 9 illustrates temperature distribution on the welded sheet at different times during stage I (Fig. 9a-d) and stage II that begins at $t=0.855 \mathrm{~s}$ (Fig. 9e). The figures show that during laser beam application, there is an important thermal gradient near the keyhole but away from heat source, the weldments temperature does not change $\left(30^{\circ} \mathrm{C}\right)$. Isotherm distribution of Fig. 9c demonstrates that the temperature, reached at the laser beam run, exceeds the AM60 magnesium alloy melting point $\left(610^{\circ} \mathrm{C}\right)$ and falls quickly enabling the solidification of material and weldments assembly. Plasma effect is noted by a larger fusion zone width on the weldment top surface where the heat input is elevated.

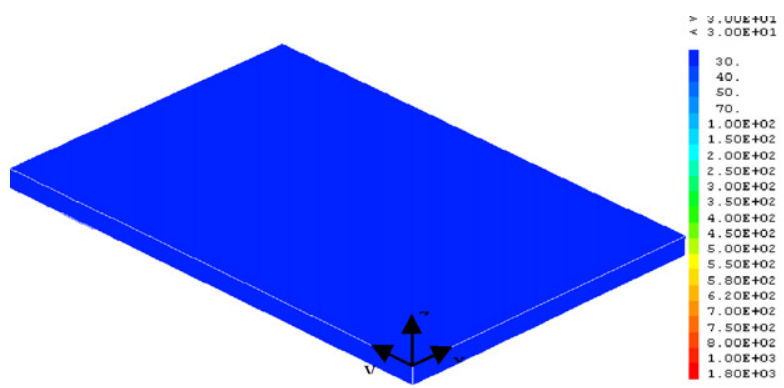

(a) : Time $=0 \mathrm{~s}$

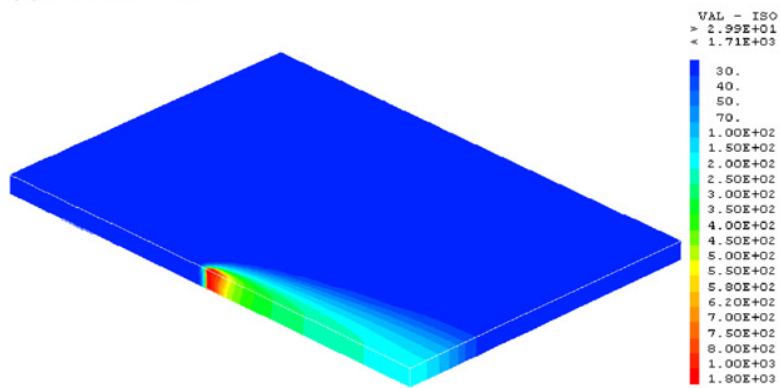

(c) : Time $=0,4275 \mathrm{~s}$

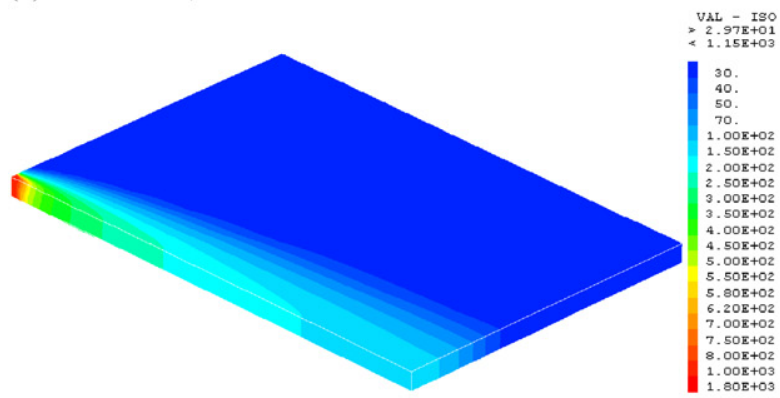

(e) : Time $=0,86 \mathrm{~s}$

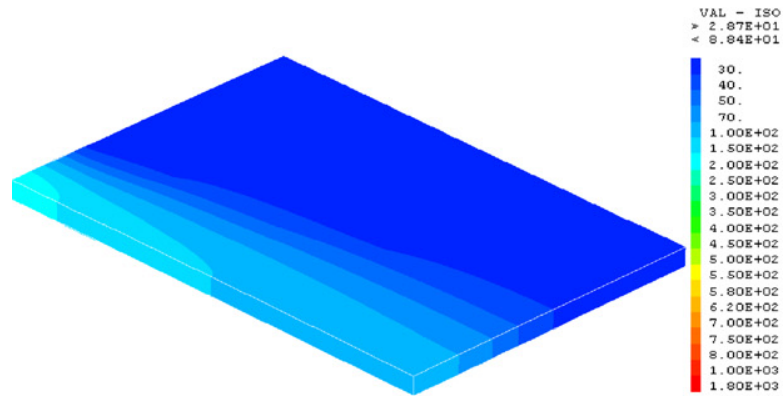

(g) : Time $=11,7 \mathrm{~s}$

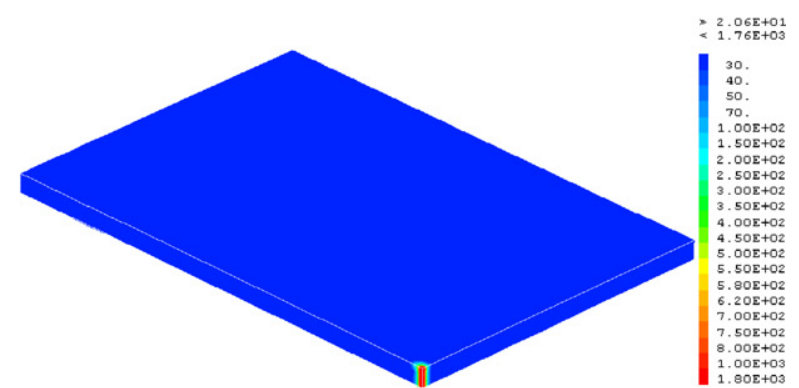

(b) : Time $=0.0057 \mathrm{~s}$

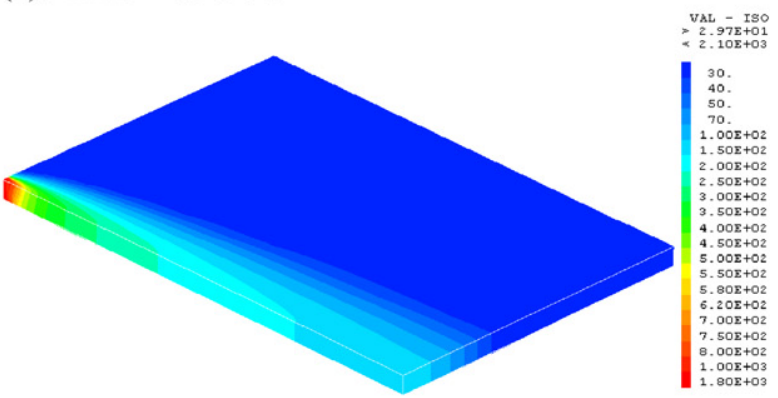

(d) : Time $=0,8493 \mathrm{~s}$

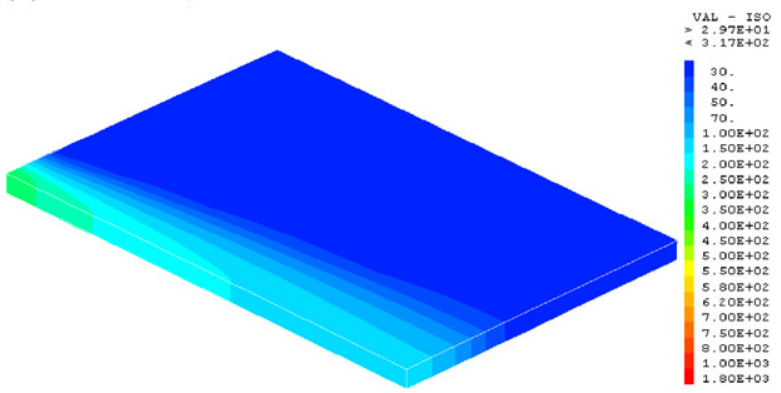

(f) : Time $=1,14 \mathrm{~s}$

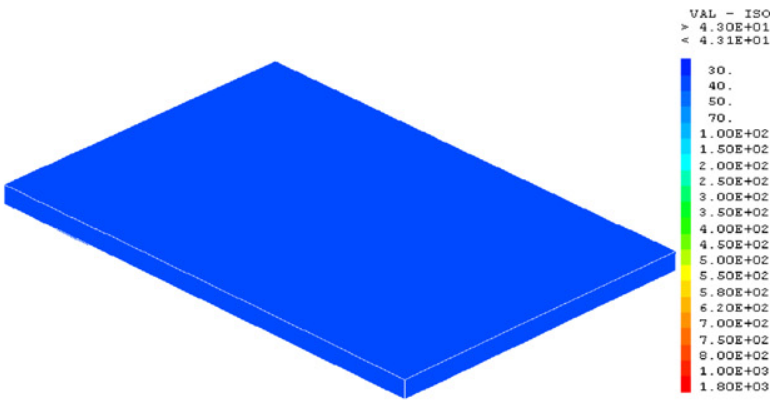

(h) : Time $=20,7 \mathrm{~s}$

Fig. 9. Isotherm evolution during laser application (a-d) and cooling (e-h). 


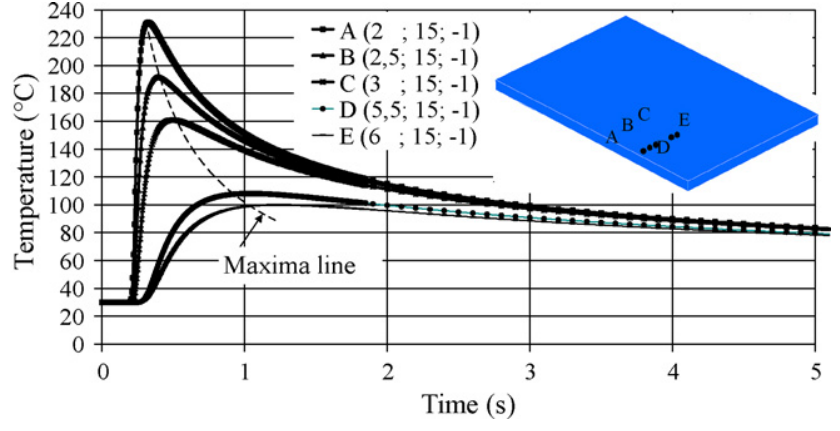

Fig. 10. Predicted temperature evolution during laser beam welding.

Fig. 10 shows simulated temperature evolutions according time, in five points A-E at different positions from weld centre-lines, since the beginning of welding until thermal balance. It can be noted that heating and cooling rates are important during laser application stage whereas during cooling, heat flow is lower.

Using temperature evolution according time, heating and quenching rate are calculated for five points situated on the molten zone (points $F$ and $G$ ) and near laser-matter interaction surface (points $\mathrm{H}-\mathrm{J}$ ). According to Fig. 11, predicted quenching rate on the melting zone exceeded $10^{4}{ }^{\circ} \mathrm{C} / \mathrm{s}$. This result is in accordance with those of Liu et al. (2005).

For experimental investigations, results concern temperature measurements during welding and weld metallurgical observations.

Fig. 12 gives K-thermocouple measured temperature during laser beam welding. The temperature evolutions according time are given for three specific points of weldment $T_{1}, T_{2}$ and $T_{3}$ representing the thermocouple position (Fig. 8). From measured evolution, we can note there are two stages of the process: the heating one for which the heating rate is important compared to quenching rate during cooling stage.

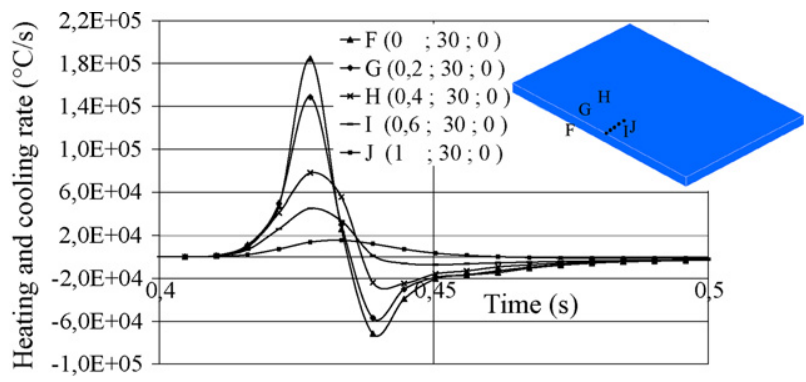

Fig. 11. Predicted heating and cooling rates evolution during laser welding.

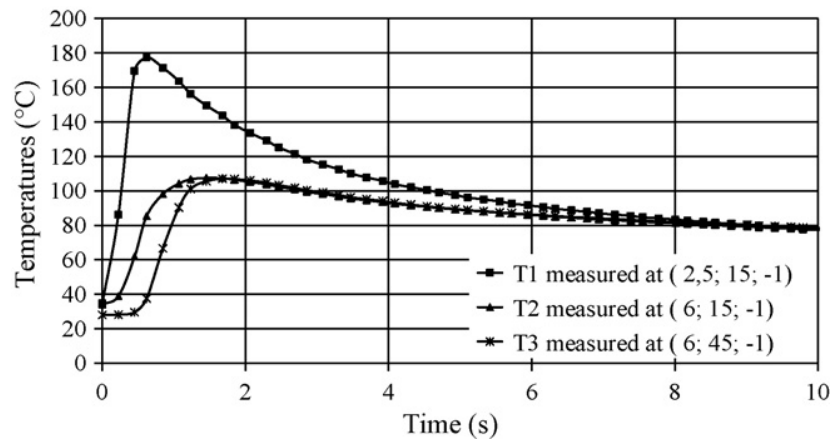

Fig. 12. Thermocouple measured temperatures.

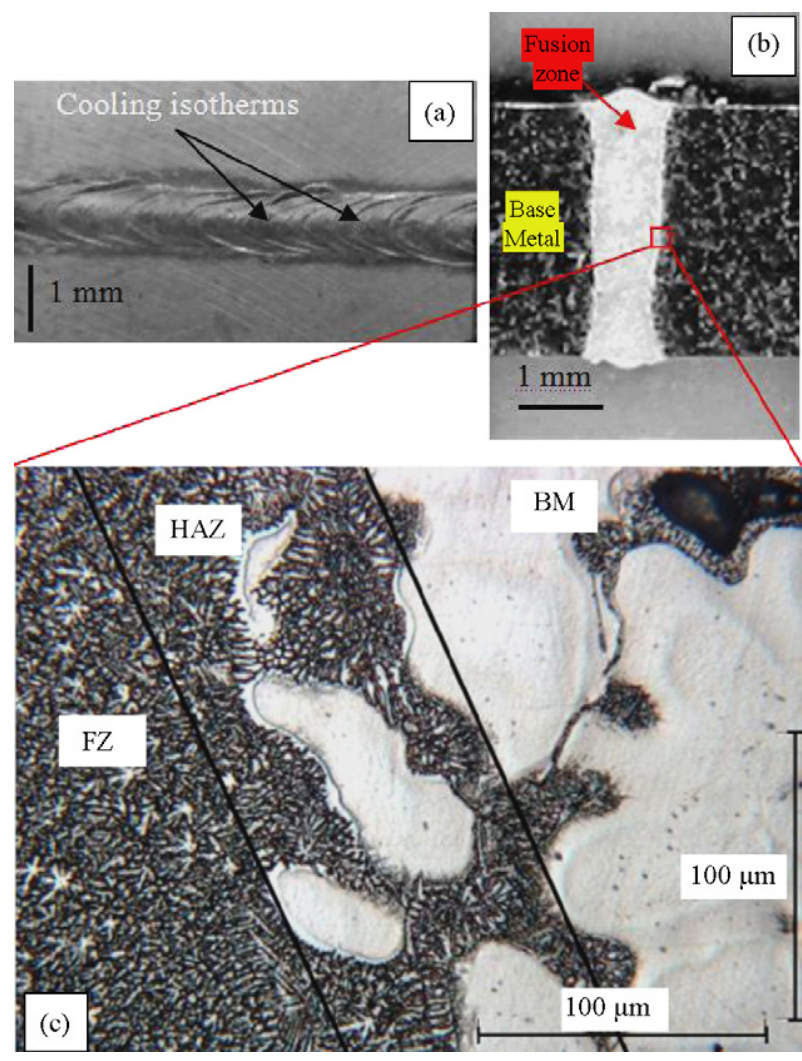

Fig. 13. Weld metallurgical observations: $\mathrm{LP}=3000 \mathrm{~W} ; V=4.2 \mathrm{~m} / \mathrm{min} ; \mathrm{FP}=0 \mathrm{~mm}$ from surface, $\mathrm{GF}=40 \mathrm{l} / \mathrm{min}$.

The metallurgical properties of laser welded joint, obtained by process parameter given in Table 3, were investigated. Transversal weld macrograph of Fig. 13b shows that, after magnesium alloy laser welding, noticeable change in microstructure occurred. Two principal zones were present: the fusion zone (FZ) and the base metal (MB). A very small heat affected zone (HAZ), with $90 \mu \mathrm{m}$ in width, was detected on weld microstructure presented in Fig. 13c. The molten zone was characterized by a dendritic microstructure. Liu et al. (2005) had observed this structure with high solidification rate of as-cast magnesium alloys melded by laser radiation.

Experimental investigations, presented above, were used to calibrate and to validate numerical results in terms of temperature evolution and weld geometrical characteristics.

According to Fig. 14, the comparison of the finite element simulated temperature evolution and those measured by thermocouples reveals a satisfactory agreement between numerical and experi-

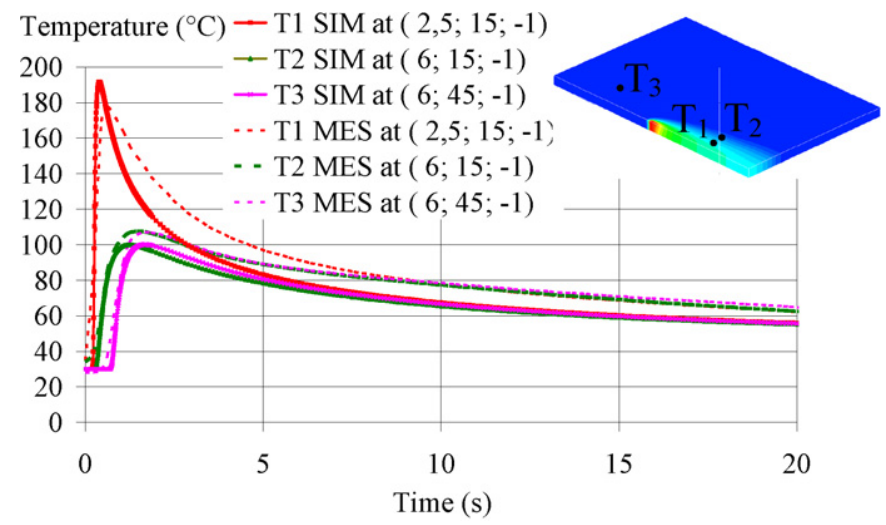

Fig. 14. Experiment vs. simulation: temperature evolution according time. 


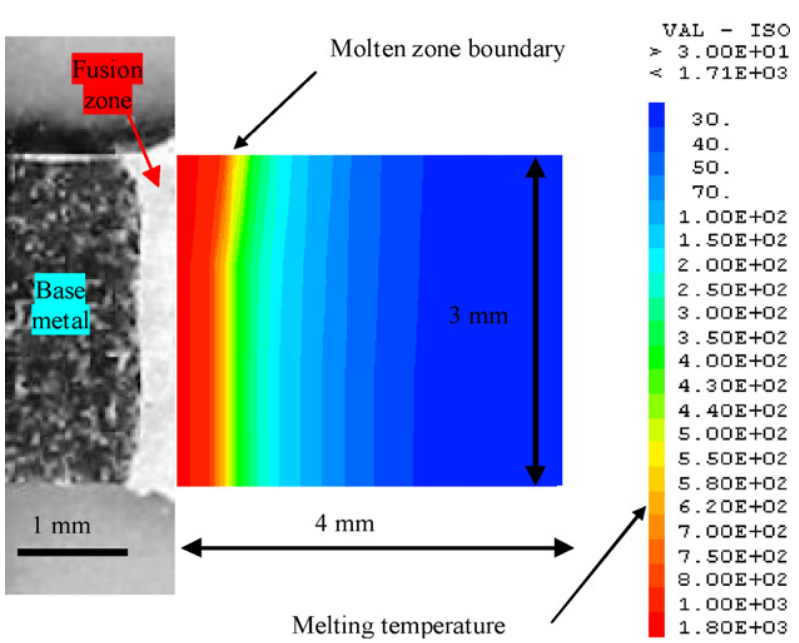

Fig. 15. Experiment vs. simulation: weld width.

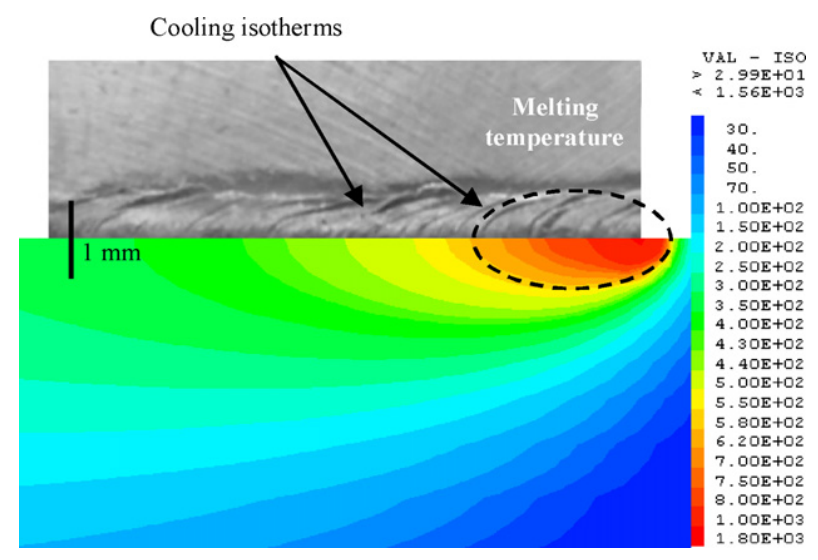

Fig. 16. Experiment vs. simulation: cooling isotherm.

mental results. The same thermal behaviour is noted during heating step. However, we can notice temperature value differences after the laser beam run. This difference can be due to considered hypothesis in the definition of the convective condition during cooling and some error calculation due to the lack of information concerning material properties especially at high temperature.

The comparison of simulated molten zone form and dimension with those determined by metallurgical investigations are presented in Figs. 15 and 16. Isotherm evolutions near heat source were compared to transversal weld macrographs (Fig. 15). With $3 \mathrm{~kW}$ laser power and $4.2 \mathrm{~m} / \mathrm{min}$ welding rate, the measured weld width was between 0.6 and $1 \mathrm{~mm}$. On the other hand, the simulated molten zone detected by melting temperature was about $0.9 \mathrm{~mm}$. Similar solidification profiles on the weldment top surface were noted comparing simulated temperature distribution near heat source and molten zone morphology (Fig. 16).

\section{Conclusion}

A 3D finite element model has been developed to simulate the thermal history during laser welding of AM60 magnesium-based alloy thin plates. The non-linear transient calculation was performed using the CAST3 M FE code. The suggested model gave the possibility to determinate at every treatment time step, the temperature fields on weldments from the beginning of welding until the return to thermal balance. Instantaneous temperatures and heating and cooling rates evolutions according time were also determined in many meshwork points. Experimental studies were conducted to validate numerical model simulations. The temperature measurement results and metallurgical investigations were in good agreement with thermal model upshots. Temperature fields at various time steps, resulting from the developed model, will be used as input on the mechanical analysis of magnesium alloys laser beam welding process.

\section{Acknowledgements}

The authors are grateful to FONDERIE MESSIER (HONSEL group) that provided the as-cast magnesium alloy workpieces. The authors would like also to acknowledge the technical support of Dr. Morraru of the IMS Laboratory, ARTS ET MÉTIERS PARISTECH, Aix En Provence, France.

\section{References}

Abderrazak, K., Bannour, S., Mhiri, H., Lepalec, G., Autric, M., 2009a. Numerical and experimental study of molten pool formation during continuous laser welding of AZ91 magnesium alloy. Computational Materials Science 44, 858-866.

Abderrazak, K., Ben Salem, W., Mhiri, H., 2009b. Nd:YAG laser welding of AZ91 magnesium alloy for aerospace industries. Metallurgical and Materials Transactions B 40, 54-61.

Abderrazak, K., Ben Salem, W., Mhiri, H., Lepalec, G., Autric, M., 2008. Modelling of $\mathrm{CO}_{2}$ laser welding of magnesium alloys. Optics \& Laser Technology 40, 581-588.

Belhadj, A., 2009. Experimental and numerical contribution laser welding study: application to magnesium alloys, Ph.D. Thesis, ParisTech University.

Bessrour, J., Bouhafs, M., Khadrani, R., Jammali, M., 2002. Modèle thermique instationnaire d'un traitement superficiel par une source laser mobile. International Journal of Thermal Sciences 41, 1055-1066.

Dhahri, M., Masse, J.E., Mathieu, J.F., Barreau, G., Autric, M., 2000. $\mathrm{CO}_{2}$ laser welding of magnesium alloys. Proceedings of the SPIE: High-Power Lasers in Manufacturing 3888, 725-732.

Dhahri, M., Masse, J.E., Mathieu, J.F., Barreau, G., Autric, M., 2001. Laser welding of AZ91 and WE43 magnesium alloys for automotive and aerospace industries. Advances in Engineering Materials 3 (7), 504-507.

Friedrich, H.E., Mordike, B.L., 2006. Magnesium Technology: Metallurgy, Design Data, Applications. Springer-Verlag, Berlin, Heidelberg.

Liu, S.Y., Hu, J.D., Yang, Y., Guo, Z.X., Wang, H.Y., 2005. Microstructure analysis of magnesium alloy melted by laser irradiation. Applied Surface Science 252 . 1723-1731.

Moraitis, G.A., Labeas, G.N., 2008. Residual stress and distortion calculation of laser beam welding for aluminium lap joints. Journal of Materials Processing Technology 198, 260-269.

Michailov, V., Stadtaus, M., Rethmeier, M., 2003. Numerical MIG-welding simulation of magnesium alloys. In: 7th International Seminar: Numerical Analysis of Weldability, Graz Seggau, Austria.

Quan, Y., Chena, Z., Gonga, X., Yua, Z., 2008. $\mathrm{CO}_{2}$ laser beam welding of dissimilar magnesium-based alloys. Materials Science and Engineering A496, 45-51.

Spina, R., Tricarico, L., Basile, G., Sibillano, T., 2007. Thermo-mechanical modelling of laser welding of AA5083 sheets. Journal of Materials Processing Technology 191, 215-219. 